\title{
Economic and Policy Implications of Industry Interdependence: An Input-output Approach
}

\author{
Daniel Gravino \\ Correspondence: Daniel Gravino, Institute for Tourism, Travel and Culture, University of Malta, Msida. E-mail: \\ daniel.gravino@um.edu.mt
}

Received: March 19, 2012

Accepted: April 20, 2012

Published: June 1, 2012

doi:10.5539/ijef.v4n6p22

URL: http://dx.doi.org/10.5539/ijef.v4n6p22

\begin{abstract}
The study provides an overview of the fundamental principles of input-output theory, the steps involved in linkage analysis and the estimation of industry multipliers. These have been estimated using a 'new' symmetric input-output table for the Maltese economy for 2007 which is used as an example to draw policy-relevant lessons for countries with relatively small open economies. On the basis of these estimates it is argued that (1) the effect of an increase in final demand will go beyond the industry directly affected by the initial change in expenditure, (2) that multipliers provide an important guide to policy makers that are concerned with making optimal use of their scarce resources, (3) that governments of countries that depend heavily on foreign direct investment can target labour intensive industries to tilt the balance in favour of the worker, (4) that a firm-specific approach is preferable to expansionary fiscal policy when a country is heavily dependent on imported products, and (5) that market distortions and inefficiencies are more damaging in those sectors that have strong forward linkages with other sectors in the domestic economy.
\end{abstract}

Keywords: input-output model, inter-industry linkages, multiplier analysis, Malta

\section{Introduction}

Input-output analysis originated in 1758 when François Quesnay published the Tableau Économique portraying the sales and purchases between the various industries and institutions in an economy. In 1874, Leon Walras further developed input-output modelling by providing a theoretical formulation of an economic system - a branch in economics today known as general equilibrium theory. However, most input-output models in operation today rely on the model developed by Wassily Leontief in 1941. His work was considered a breakthrough in relating Walras' general equilibrium theory to data for the American economy. By bringing together the theoretical framework of industry interdependence and data, input-output analysis could be used as a guide for policy decisions. Indeed, to this day it has been applied to the areas of environment, trade, productivity and industry impact analysis amongst others.

Input-output analysis becomes indispensible for rational policy formulation where two conditions hold: (1) inputs as well as outputs enter society's objective function directly (as in the case of employment, limited energy resources and pollution) and (2) where the economy in question is open, so that macroeconomic policy is largely powerless to increase employment or to influence the use of other inputs (Baumol and Wolff, 1994). Economies the world over are becoming increasingly open, none more so than Malta where exports and imports together amount to around 200\% of GDP. Thus, the study of industry interdependence in Malta provides an interesting application of input-output analysis and will be used as an example to draw policy-relevant lessons for Malta and more generally for countries with relatively small and open economies.

Officially published for the first time in the early 1960s, the Maltese industrial input-output table focused solely on direct production sectors of the economy. The last publication of the table dates back to the 1998 issue of the National Accounts of the Maltese Islands. Since then, the Maltese economy has undergone significant restructuring, not only away from direct production and towards market services, but also within the direct production sector itself. In 2010, market services accounted for 59\% of Malta's Gross Domestic Product (GDP), up from 48\% in 1998. To a large extent this reflects developments in the real estate, renting and business activities sector as well as the other community, social and personal activities sector (Note 1). Activity within the manufacturing sector itself has also shifted towards higher value-added activities as evidenced by the decreasing share of the manufacturing of textiles sector and the emergence of the pharmaceutical and aviation maintenance industries. Thus, any serious analysis of 
the Maltese economy at a micro or sector level calls for the development of an input-output table based on more recent data that reflects these developments.

Seen in this light, the paper is intended to serve two goals. First it has the purpose to act as a guide to the steps involved in the specification and application of an input-output model. Second, it attempts to draw policy-relevant conclusions from applications of a 'new' industry-by-industry input-output table constructed for the Maltese economy for 2007. Issues relating to the theoretical foundations of input-output analysis and the construction of the 'new' table are presented in section 2. Multiplier and linkage analysis follow in sections 3 and 4 respectively, while section 5 discusses the limitations of the analysis and section 6 concludes.

\section{Theoretical Foundations of Input-output Analysis}

A symmetric input-output table traces the path by which incomes flow through the economy between producers and consumers. On the one hand, it shows how the output of each sector is distributed among institutions and other industries in the economy. On the other, it shows the inputs to each industry from other industries and institutions. These are algebraically represented in Table 1 in order to facilitate the discussion.

The heart of the input-output table is the inter-industry transactions table. It depicts the production relationships in the economy as represented by elements $x_{i j}$. In this table, the column sectors are consuming sectors and the row sectors are the producing sectors. Thus, any one element in the matrix represents the output value that the row sector delivers to the column sector. It follows that the sum across columns of the inter-industry matrix is the intermediate outputs vector, while the sum across the rows is the intermediate inputs vector.

Table 1. Algebraic Input-Output Table

\begin{tabular}{c|ccc|c|c}
\hline & $\mathrm{A}$ & $\mathrm{B}$ & $\mathrm{C}$ & $\mathrm{FD}$ & $\mathrm{T}$ \\
\hline $\mathrm{A}$ & $\mathrm{x}_{11}$ & $\mathrm{x}_{12}$ & $\mathrm{x}_{13}$ & $\mathrm{y}_{1}$ & $\mathrm{z}_{1}$ \\
$\mathrm{~B}$ & $\mathrm{x}_{21}$ & $\mathrm{x}_{22}$ & $\mathrm{x}_{23}$ & $\mathrm{y}_{2}$ & $\mathrm{z}_{2}$ \\
$\mathrm{C}$ & $\mathrm{x}_{31}$ & $\mathrm{x}_{32}$ & $\mathrm{x}_{33}$ & $\mathrm{y}_{3}$ & $\mathrm{z}_{3}$ \\
\hline $\mathrm{FP}$ & $\mathrm{v}_{1}$ & $\mathrm{v}_{2}$ & $\mathrm{v}_{3}$ & & \\
& $\mathrm{~m}_{1}$ & $\mathrm{~m}_{2}$ & $\mathrm{~m}_{3}$ & & \\
\hline $\mathrm{T}$ & $\mathrm{q}_{1}$ & $\mathrm{q}_{2}$ & $\mathrm{q}_{3}$ & & \\
\hline
\end{tabular}

The quadrant made up of elements $y_{i}$ describes consumption behaviour, characterised by the consumption patterns of households, government and investors as well as exports. Since goods transferred to these institutions would not normally reappear in the economy, these are grouped under the final demand (FD) category.

The final payments (FP) quadrant incorporates two major variables, namely, value-added and imports. The latter consists of sectoral imports $\left(m_{j}\right)$ while the former represents wages and salaries, profits, interest, dividends and taxes. It is called sectoral value-added $\left(v_{j}\right)$ because it is the value that a sector adds to the goods and services it uses as inputs in order to produce a final product. Thus the value-added vector measures each sector's contribution to GDP.

From a circular flow perspective, the final demand quadrant is where the spending cycle begins and where the finished goods end up to satisfy the needs of consumers. The final payments quadrant is where the production cycle starts, with households and other resource owners receiving compensation for their contribution to the production process. The overlap between these two cycles is represented by the inter-industry transactions matrix that traces the relationships describing the technology of production of the various sectors in the economy.

A concise way of representing the relationship between all three quadrants is to use matrix algebra. Viewed as an equilibrium model, the data in the input-output table can be expressed in terms of identities, behavioural assumptions and equilibrium conditions (Schaffer, 1999). The set of identities is given by

$$
z_{i}=\sum_{j} x_{i j}+y_{i}
$$

and

$$
q_{j}=\sum_{i} x_{j i}+v_{j}+m_{j}
$$

where $z_{i}$ is total demand, $x_{i j}$ are sales by sector $i$ to sector $j, y_{i}$ is final demand, $q_{j}$ is total supply, $x_{j i}$ is the sum of all purchases by sector $j$ from sectors $i, v_{j}$ is sectoral value added and $m_{j}$ are sectoral imports. 
The equilibrium condition is based on the assumption that over a long period of time it is irrational to supply more than is used and impractical to consume more than is produced. Hence, it must hold that for every sector

$$
q_{j}=z_{i}
$$

such that column totals equal row totals for all sectors in the economy.

The behavioural assumption is then given by

$$
a_{i j}=x_{i j} / q_{j}
$$

where $a_{i j}$ is the technical coefficient showing the proportion in which inputs of each sector combine the goods and services which they purchase to produce their own output. In other words, if $a_{21}$ is 0.5 it means that $50 \%$ of sector A's inputs are supplied by sector B. Whilst this indicator per se is already very informative and useful for the formulation of policy, the contribution of the input-output table to analytical purposes does not end here. In addition to providing a detailed breakdown of sector inputs, the input-output table can be used to calculate the indirect impacts on the economy as each sector affected directly by changes in final demand turns to other sectors for inputs. This thinking sets the stage for the topic of the next section: the multiplier analysis.

\section{Multiplier Analysis}

In practice, the multiplier is one of the more useful analytical techniques. It is a ratio that measures the impact on the total economy as a result of an initial autonomous change in any of the final demand components. While the impact on the industries directly affected by a change in demand can be measured with relative little difficulty, when one recognises the interdependence of economic activity, it is apparent that the total impact will not be limited to the sectors directly affected by the initial change in demand.

An aggregative multiplier - as originally developed by John Maynard Keynes (1936) - is a useful analytical tool, but it does not show the details of how multiplier effects work through the economy. Indeed, some advantage is gained by disaggregation. Consider the case of an increase in the demand for financial services. To increase its service provision, the financial services sector will demand more computers, electricity and stationery. The manufacturers of stationery and computers and the providers of electricity will in turn have to buy more raw materials and fuel to increase their production. Although part of this expenditure will finance import consumption and hence leaks out of the economy, the intermediate purchases process will continue to repeat itself until leakages reduce the effect of the initial increase in the demand for financial services to a negligible amount.

This process can be conveniently expressed using the mathematical representation adopted in section 2 . Substituting $a_{i j} q_{j}$ for $x_{i j}$ in equation (1) and $q_{j}$ for $z_{j}$ in equation (4) gives

$$
q_{i}^{\prime}=\sum_{j} a_{i j} q_{j}^{\prime}+y_{i}^{\prime}
$$

Assuming $A$ to represent the matrix made up of $a_{i j}$ and $y$ to represent the column vector $y_{i}$ we get

$$
q=(I-A)^{-1} y
$$

Equation (6) gives the well known static input-output system developed by Leontief (1966). The core of the model lies in the $i$-by- $j$ Leontief Inverse matrix $(I-A)^{-1}$. Also known as the total requirements matrix, it portrays the relationship between final demand (y) and total output (q). Whilst in the direct requirements matrix $A$, elements $a_{i j}$ represent the (direct) inputs from sector $i$ to produce a euro worth of sector $j$ 's output, the corresponding elements in the Leontief inverse matrix represent the direct as well as the indirect increase in production of sector $i$ following a euro increase in sector $j$ 's output.

Formally the Leontief inverse matrix can be expressed as an iterative procedure that captures both the direct and indirect requirements for domestic intermediates following a one euro change in final demand. This can be written as

$$
(I-A)^{-1} y=y+A y+A^{2} y+\ldots+A^{n} y
$$

Where matrix $A$ represents the direct input requirements and matrices $A^{2}$ to $A^{n}$ represent the indirect requirements for intermediates at the previous stages of production. Each term is calculated as the previous indirect effect multiplied by the direct requirements matrix. Since each element in the direct requirements matrix is less than one, each successive term representing indirect effects is smaller than the previous.

Using equation (6), the total impact on an economy's output following a change in final demand is given by

$$
\Delta q=(I-A)^{-1} \Delta y
$$


such that the output multiplier is equal to the change in total output $(\Delta q)$ divided by the change in final demand $(\Delta y)$. For an individual industry $j$, the output multiplier is given by

$$
\text { mult }_{\text {OUT }_{j}}=\sum_{i} T R_{i j}
$$

where $T R_{i j}$ is the total requirements matrix $(I-A)^{-1}$. Therefore, the output multiplier for industry $j$ is simply the sum of column $j$ in the total requirements matrix across all industries $i$. Combining the equation for the output multiplier with the technical coefficients for value added we get the value added multiplier

$$
\text { mult }_{V A_{j}}=\sum_{i}\left(v_{j} / q_{j}\right) T R_{i j}
$$

Similarly, we can get income and employment multipliers by combining equation (9) with the technical coefficient for income and the employment-output ratio respectively. The income multiplier is given by

$$
\text { mult }_{I N C_{j}}=\sum_{i}\left(w_{j} / q_{j}\right) T R_{i j}
$$

where $w_{j}$ is the wage share in total output of sector $j$. The employment multiplier is given by

$$
\text { mult }_{E M P_{j}}=\sum_{i}\left(e_{j} / q_{j}\right) T R_{i j}
$$

where $e_{j} / q_{j}$ is the employment-output ratio.

It is clear that the estimates of multipliers depend on the transactions matrix $A$. The matrix should include all those sectors and institutions which base their buying decisions on their incomes. In the input-output model, these activities are assumed endogenous since their behaviour is determined within the system. Other activities of final demand, such as exports, are decisions made outside the system and so are called exogenous activities. More specifically, industries are normally classified as endogenous while final demand institutions are normally considered exogenous. However, this distinction is not quite clear cut.

While traditionally the household sector is classified as a final demand institution, it is frequently treated as part of the transactions table. Households sell labour and managerial skills to industries and receive wages and salaries in return. With the income they receive they buy food, clothes and other products and set in motion a new cycle. Accounting for approximately $17 \%$ of total expenditure, the household institution is a critical part of the Maltese economy. Hence, the compensation of employees and household expenditure are sometimes incorporated within the transactions matrix A. Thus, the multipliers referred to above can be generated from two different models, namely, Type I and Type II.

The Type I multiplier is sometimes referred to as a "simple" multiplier since it takes into account only direct and indirect changes resulting from of a euro increase in final demand. It covers both the change in industrial purchases of industries directly affected by the change in final demand and also the change in purchases of those industries indirectly affected by the change in demand. Type II multipliers are a more realistic measure which take into account the direct and indirect effects plus induced changes in income resulting from increased consumer spending. The induced effect reflects the change in consumer spending that is generated by changes in labour income as a result of direct and indirect effects of an economic activity. Thus, for each sector, the Type II multiplier will always be larger than its Type I counterpart. Miller and Blair (2009) pointed out that "it is generally conceded that Type I multipliers probably underestimate economic impacts (since household activity is absent) and Type II multipliers probably give an overestimate (because of the rigid assumptions about labour incomes and attendant consumer spending)."

On the basis of the above discussion, this section presents estimates and analysis for both these multipliers for the Maltese economy. In contrast to previous input-output analysis for the Maltese economy - which focused solely on tourism multipliers (Briguglio, 1992; Mangion and Vella, 2000; Blake, Sinclair and Sugiyarto, 2003) - the study presents multiplier estimates for major industries in the Maltese economy so as to provide a guideline for industrial policy formulation. These were estimated using the 'new' input-output table which has been constructed on the basis of the 2001 Supply and Use Tables (SUT) published by Malta's National Statistics Office. Following the conversion of SUT into similar prices, these have been transformed into a symmetric input-output table using the fixed product sales structure methodology, an assumption commonly adopted by a number of national statistical agencies worldwide, including Denmark, Hungary, the Netherlands, Finland, Canada and Norway (Eurostat, 2000) (Note 2). Compared to the 1998 input-output table, the 'new' input-output table covers a wider range of sectors, in part reflecting the restructuring the Maltese economy has undergone throughout the past decade. 
Table 2 presents the Type I multiplier estimates for ten major industries in the Maltese economy. It shows that the output multiplier is highest in the transport and communication sector at 1.43. This means that an increase in demand for the transport and communication sector's output would stimulate a relatively high level of domestic output in the Maltese economy. Specifically, a $€ 1$ increase in the demand for transport and communication products and services would result in an additional $€ 0.43$ increase in output in the economy. More generally, while the direct effect of a euro increase in output is one, the total average impact is 1.34 , implying that the final impact on output is greater than the initial change in final demand.

Table 2. Type I Multipliers

\begin{tabular}{lcccc}
\hline & Output & Value-added & Income & Employment \\
\hline Agriculture & 1.43 & 0.66 & 0.21 & 0.000026 \\
Manufacturing & 1.42 & 0.48 & 0.26 & 0.000017 \\
Electricity, gas and water supply & 1.26 & 0.48 & 0.66 & 0.000035 \\
Construction & 1.36 & 0.73 & 0.36 & 0.000043 \\
Commerce* & 1.39 & 0.82 & 0.38 & 0.000036 \\
Transport and communication & 1.43 & 0.69 & 0.31 & 0.000020 \\
Financial services & 1.25 & 0.93 & 0.75 & 0.000027 \\
Business services & 1.33 & 0.88 & 0.24 & 0.000020 \\
Public Administration & 1.28 & 0.89 & 0.68 & 0.000031 \\
Other services** & 1.28 & 0.88 & 0.50 & 0.000031 \\
\hline
\end{tabular}

*Includes wholesale and retail trade, hotels and restaurants.

**Includes education, health, cultural and gaming activities.

Although the output multiplier represents total requirements per euro of final output, it is not a particularly useful concept except as an indicator of the degree of structural interdependence between industries in the economy. When analysing impacts on the economy, we are more interested in income and employment multipliers. They are of particular interest because they represent income to people and jobs and therefore have a direct impact on household welfare. Indeed, at a macro level, estimates of impacts on the economy are measured as per change in GDP and not output. As noted in section 2, this is equivalent to value added. Hence, the final impact on the Maltese economy can be estimated using value added multipliers.

This was highest for the financial services sector, followed by relatively high value-added multipliers for other service activities such as other services, public administration, business services and commerce. The results show that a euro increase in the financial services sector would generate $€ 0.93$ of value added in the economy. In contrast, a euro increase in the consumption of manufacturing goods would result in only $€ 0.48$ of value added in the economy. Consequently, it can be argued that more value added is generated in the economy by $€ 1$ expenditure on financial services output than by expenditure on manufacturing goods worth an equivalent amount.

This might suggest that the contribution of the financial services sector to the Maltese economy is greater than that of the manufacturing sector. However, this statement may not necessarily be correct. First, the high level of sectoral aggregation may not reflect the true impact that some sectors have on the economy. The high value-added pharmaceutical sub-sector within the manufacturing sector is a case in point. Because the manufacturing sector largely consists of sub-sectors with low value added coefficients, using the manufacturing sector's value added multiplier as a proxy for the impact of investment in pharmaceutical companies would be misleading. Thus, a higher level of disaggregation would render the results of the analysis more suitable for the purposes of policy making. Second, the multipliers only present results per euro increase in final demand and do not account for the size of the sector. Thus, it could very well be the case that investment in a sector with a low value added multiplier would have a relatively large impact on the economy if the level of investment is significantly large. Perhaps the best example of that is the relatively large electronics sub-sector in the Maltese economy that has a low value added coefficient of 0.25 . If demand for the output of this sub-sector were to suddenly collapse to zero, it is estimated that it would impact the Maltese economy by as much as $4.5 \%$ of GDP due to the fact that it accounts for approximately $50 \%$ of Malta's exports of goods.

Another important point relates to the fact that the value-added multiplier for all sectors is less than one. This means that an additional euro of expenditure will generate a total impact on the country's GDP which is less than $€ 1$. This has significant policy implications. Consider the case where the Maltese government adopts an expansionary fiscal policy and increases its expenditure by the sum of $€ 1$ million. If this were to be spent on the construction sector, 
according to the estimates presented in Table 2, this would increase GDP by $€ 730000$ when indirect effects are also included - some $€ 270000$ less than the initial expenditure. Although part of this leakage may be related to saving and taxes which may be later re-spent in the Maltese economy, the bigger share of this leakage relates to imports. If one thinks of imported products as substitutes for local production, this becomes a crucial observation. Indeed, one of the more important lessons from the application of input-output analysis is that the more a country depends on imported goods and services instead of its own production, the more economic activity leaks away from the local economy and consequently the lower the impact of a given level of stimulus to the economy. This goes some way to justify the firm-specific targeted approach typically adopted by governments in small island states when their economies are in distress.

Table 2 also shows estimates for income multipliers. They reveal that portion of the value added multipliers that relates to wages and salaries rather than profits (Note 3). More specifically, it shows labour income generated in the Maltese economy following a euro increase in demand. It is highest in financial services, public administration and electricity sectors, indicating that all three sectors are relatively labour intensive. For example, income would be expected to increase by $€ 0.75$ following a euro increase in demand for financial services, partly reflecting the high ratio of wages to total output for the sector. Similarly, low income multipliers for some sectors, such as agriculture and business services, reflect a low wage share in total industry output. This has important implications for small open economies like Malta which tend to depend heavily on foreign direct investment to generate economic growth. Typically, a significant share of profits earned by these multinationals are remitted abroad such that a large share of value added generated by operations in a subsidiary company in Malta leak out of the Maltese economy. Within this context, governments in countries which depend heavily on foreign direct investment ought to encourage investment in labour intensive industries such that they minimise the share of value added that leaks out of their economies.

A closely related concept is the employment multiplier which, in practice, is the most commonly sought multiplier. This is due to the fact that economic impact analysis is often preoccupied with the employment effects of industrial expansion or company closures. For each sector, the employment multiplier represents jobs created per euro of additional final demand. For example, if the final demand for the construction sector were increased by $€ 1$ million, a total of 43 jobs would be created in the economy. Table 2 shows that in the case of Malta the employment multipliers are highest in the construction and commerce sectors.

Despite the usefulness of the Type I multiplier, almost all input-output analysts nowadays use Type II multipliers simply because any realistic estimates of impacts caused by changes in final demand should not overlook the relations between household income and spending. As noted above, an autonomous increase in expenditure will generate more economic activity and therefore create new employment opportunities which, in turn, increase personal income. Since household consumption expenditure is understood to depend primarily on disposable income, for purposes of the estimation of the Type II multiplier the household sector has been incorporated into the transactions table $A$. This captures the process that an increase in household income leads to increases consumption expenditure and generates a new stimulus which sets in motion further rounds of interdependent transactions.

Indeed, the Type II multiplier does not only capture direct and indirect impacts, but also includes the induced effect. The Type II multipliers for output, value added, income and employment are shown in Table 3. It is noticed that in some cases sector rankings of the Type I and Type II multipliers differ. This difference is attributed to the consumption induced effect and is, as expected, relatively higher for the more labour intensive sectors.

Table 3. Type II Multipliers

\begin{tabular}{lcccc}
\hline & Output & Value-added & Income & Employment \\
\hline Agriculture & 1.89 & 0.77 & 0.26 & 0.000029 \\
Manufacturing & 1.97 & 0.61 & 0.32 & 0.000021 \\
Electricity, gas and water supply & 2.66 & 0.80 & 0.82 & 0.000046 \\
Construction & 2.13 & 0.91 & 0.45 & 0.000050 \\
Commerce* & 2.21 & 1.01 & 0.47 & 0.000043 \\
Transport and communication & 2.08 & 0.85 & 0.38 & 0.000026 \\
Financial services & 2.84 & 1.30 & 0.93 & 0.000040 \\
Business services & 1.83 & 1.00 & 0.29 & 0.000024 \\
Public Administration & 2.73 & 1.23 & 0.84 & 0.000043 \\
Other services** & 2.34 & 1.13 & 0.62 & 0.000040 \\
\hline
\end{tabular}

*Includes wholesale and retail trade, hotels and restaurants.

**Includes education, health, cultural and gaming activities. 
Adopting an interpretation similar to that of Type I multipliers, the higher the Type II multipliers the greater the impact on the economy following some change in final demand. The relatively high multipliers for the other services, financial services, public administration and electricity, gas and water supply sectors are indicative of the strong economic linkage of these sectors with other sectors in the economy. The relatively low multipliers for sectors such as business services and manufacturing indicate that they have relatively little connection with other domestic sectors.

In contrast with the results derived from the Type I multiplier model, the Type II output multiplier is highest in the financial services sector. Overall, there is a shift at the top of the rankings from those sectors that are intensive in the use of intermediate inputs towards those that are labour intensive. Indeed, while agriculture, transport and manufacturing topped the rankings for the Type I output multiplier, it is financial services, public administration and the electricity sectors that top the rankings for Type II output multipliers. However, value added, income and employment Type II multipliers all seem to yield similar results in terms of ranking to the corresponding Type I multipliers.

The problem with the Type II multiplier is that it assumes zero taxes on household income and zero household savings. Consequently, Type II multipliers tend to overestimate the "true" impact on the economy. An attempt to overcome this and other deficiencies in the standard input-output model was undertaken by Bonnici (1980). However, results are not directly comparable to the estimates presented in this paper.

\section{Linkage Analysis}

The multiplier analysis is useful when interest lies in estimating the impact of changes in final demand but ignores the role of supply. Linkage analysis overcomes the one-sided view of a demand-led economy by considering both forward and backward linkages. Backward linkages capture the linkages of a sector with upstream industries (i.e. sectors from which the sector purchases inputs) while forward linkages capture linkages with downstream industries (i.e. sectors to whom the sector sells its output). In other words, forward linkages capture changes in the downstream sectors' output as a result of a one unit increase in value added in a particular sector while backward linkages capture changes in the upstream sectors' production driven by a one unit increase final demand.

When backward linkage analysis is understood to include both direct and indirect effects (Yotopoulos and Nugent, 1976) the backward linkage is equal (or proportional) to the Type I output multiplier discussed in section 3. Forward linkages are similar but work in the opposite direction. Instead of considering the demand created by (say) the electricity sector, increased output in the electricity sector is viewed as being supplied to other sectors in the economy. This type of analysis would be particularly useful if one were to consider competitiveness implications following an increase in electricity prices.

Following the work of Ghosh (1958), rather than assuming that intermediate inputs are proportional to column totals, forward linkage analysis assumes that they are proportional to row totals. This is given by

$$
b_{i j}=x_{i j} / z_{i}
$$

such that intermediate flows are supply-led rather than demand-led. Therefore, whilst backward linkages are computed using input coefficients as per equation (3), forward linkages are estimated using output coefficients as per equation (13). Formally, the forward linkage of industry $j$ is given by

$$
F L_{j}=\sum_{j} T O_{i j}
$$

where $T O_{i j}$ is the total output matrix $(I-B)^{-1}$ and B is a matrix made up of elements $b_{i j}$.

Table 4 shows the backward and forward linkages for the ten sectors under analysis. Following Rasmussen (1956) the estimates have been normalised to one such that a backward linkage greater than one implies that the sector has above average dependency on domestic sectors for its input requirements and is thus backward oriented. The opposite is true for values less than one. On the other hand, a forward linkage greater than one implies that domestic sectors have above average dependency upon the sector in question and is thus forward oriented. On this basis, it is possible to identify sectors with the strongest linkages across the whole economy as those which are simultaneously forward and backward oriented.

The analysis also makes a distinction between sectors whose inter-linkages are spread over many sectors in the economy and sectors whose inter-linkages are concentrated in a few sectors. As suggested by Boucher (1976), this can be measured by the coefficient of variation which is simply the standard deviation divided by the mean. The backward coefficient of variation is thus given by 


$$
\operatorname{COV}_{B}=\frac{\sqrt{\left(\frac{1}{n-1}\right) \sum_{i}\left(T R_{i j}-\frac{1}{n} \sum_{i} T R_{i j}\right)^{2}}}{\frac{1}{n} \sum_{i} T R_{i j}}
$$

and the forward coefficient of variation is given by

$$
C O V_{F}=\frac{\sqrt{\left(\frac{1}{n-1}\right) \sum_{j}\left(T O_{i j}-\frac{1}{n} \sum_{j} T o_{i j}\right)^{2}}}{\frac{1}{n} \sum_{j} T O_{i j}}
$$

A low coefficient of variation in a particular sector indicates that investment in that sector would stimulate all domestic sectors in the economy relatively evenly. On the other hand, a high coefficient of variation means that the stimulus generated by investment in a particular sector is unevenly shared amongst all sectors. Therefore any given sector's importance in the economy is greater if the estimated linkage is relatively large and the coefficient of variation relatively small.

Table 4. Backward and Forward Linkages

\begin{tabular}{lcccc}
\hline & \multicolumn{2}{c}{ Backward } & \multicolumn{2}{c}{ Forward } \\
& Linkage & Coeff. of variation & Linkage & Coeff. of variation \\
\hline Agriculture & 1.02 & 2.25 & 0.99 & 2.20 \\
Manufacturing & 0.92 & 2.50 & 0.88 & 2.91 \\
Electricity, gas and water supply & 0.98 & 2.30 & 1.40 & 1.45 \\
Construction & 1.01 & 2.22 & 0.84 & 2.63 \\
Commerce* & 1.04 & 2.41 & 0.93 & 2.35 \\
Transport and communication & 0.91 & 2.57 & 1.04 & 2.17 \\
Financial services & 0.97 & 2.39 & 1.33 & 1.66 \\
Business services & 0.94 & 2.70 & 1.05 & 2.15 \\
Public Administration & 0.95 & 2.38 & 0.75 & 2.87 \\
Other services** & 1.27 & 1.93 & 0.79 & 2.87 \\
\hline
\end{tabular}

*Includes wholesale and retail trade, hotels and restaurants.

**Includes education, health, cultural and gaming activities.

The results presented in Table 4 show that the electricity, gas and water supply sector and the financial services sector had the highest forward linkages and lowest coefficients of variation, suggesting that the two sectors play a key role in providing inputs to all domestic sectors in the economy. In continuation with the previous example, this would mean that higher prices charged by the electricity sector would probably result in higher costs to most other sectors in the economy.

The estimates also show that the backward linkages are highest in the other services sector, indicating that the sector is highly dependent upon other domestic sectors for its input requirements. The desirability for high backward linkages stems from the increase in other sectors' output to meet the demand generated by a sector's intermediate input requirements. At the same time, backward linkages were lowest in the transport and communications sector. The similar results observed for output multipliers in section 3 come as no surprise as the backward linkages $a ̀$ la Yotopoulos and Nugent (1976) are proportional to the output multiplier estimates.

\section{Limitations}

The analysis presented in sections 3 and 4 demonstrates the usefulness and practical implications of input-output modelling. However, a comprehensive understanding of the informational value-added gained through input-output analysis necessitates that one also understands its limitations. While some are subject to the modelling choices of the analyst, others are implicit in the static input-output model developed by Leontief.

First, multipliers focus on the demand-side of the economy. They ignore the supply-side and capacity constraints, and are thus short run in nature. Indeed, they might be thought of in the tradition of Keynesian macroeconomics. In practice, this means that following an increase in demand, the Leontief multiplier may predict increases in output which violate the supply constraints of the economy. A second and equally 'restrictive' assumption is that the Leontief multiplier is based on a fixed price assumption. In practice, however, the reallocation of resources resulting 
from shocks to the economy has implications for both demand and supply-sides of the economy, thereby distorting commodity prices and returns to factors of production. To overcome both these deficiencies the analysis would require a general equilibrium approach capturing the supply and demand relationships between all interconnected sectors in the economy, with prices providing the common flow of information needed to coordinate the system. If this were the case, the model is likely to predict lower sector impacts, implying that the input-output model might overestimate the "true" impact following some shock in final demand.

Third, the input-output applications assume that there are no economies of scale. This means that the proportion of inputs used in a particular sector's production process do not change regardless of the level of production. This limitation would be particularly significant if there are significant changes in final demand.

Fourth, while the table has been constructed at the highly disaggregated level of sixty industries and ninety-two products, for the purposes of this paper it is aggregated to ten sectors. Through aggregation and alteration of sector definitions the relative importance of sectors might change significantly. Furthermore, a high level of aggregation may itself lead to some inaccurate conclusions because it changes input and output coefficients, and thereby affects the estimated impact of a particular sector on the economy.

Despite these limitations, input-output modelling remains one of the most accepted means of estimating sectoral impacts. Whilst it is true that economic modelling has come a long way since the first applications of input-output modelling, this type of analysis still offers a unique contribution through its ability to shed light on issues of sectoral economic impacts and the identification of key sectors in the economy. Furthermore, because input-output tables provide a system that incorporates the various sectors of the economy in a form coherent with economic theory, they still play a critical role in the formulation of larger scale models such as social accounting matrices, macro-econometric models as well as the increasingly popular computable general equilibrium models (Dervis, de Melo and Robinson, 1982).

\section{Policy-relevant Conclusions}

The study provides an overview of the fundamental principles of input-output theory, the steps involved in linkage analysis and the estimation of industry multipliers. These have been estimated using a 'new' symmetric input-output table for the Maltese economy for 2007. It differs from previous input-output tables for Malta which focused on the production side of the economy and ignored important aspects of the services sector. Constructed in line with the requirements set forth by the European Commission's statistical arm, Eurostat, the estimates should also serve as a benchmark for all input-output tables to be constructed for the Maltese economy in the future. In addition, the estimated industry multipliers may be an important input into the decision making process for Maltese policymakers. More generally, the study makes five major policy-relevant conclusions.

First, in line with standard input-output analysis, it shows that the effect of any increase in final demand will go beyond the industry directly affected by the increase in expenditure. This is because the directly affected industry turns to other industries for inputs in order to meet the increase in demand.

Second, although individual industry multipliers are indicative of the extent of a sector's linkages with other industries and institutions in the economy, it need not necessarily imply that the greatest contributions to a country's economy are from those industries with larger multipliers. Indeed, it would be naïve to play down the contribution of a relatively large sector because of its relatively small multiplier. However, it would be correct to say that investment in a sector with a relatively large multiplier (or equivalently a high backward linkage) would generate a greater contribution to the economy than an equal sum invested in a sector with a lower value added multiplier. Thus, industry multipliers provide a significant guide to policy makers in small open economies that are particularly concerned with making optimal use of their scarce resources.

Third, irrespective of the impact on GDP, the analysis shows that employment and income multipliers will be greater for expenditures on labour intensive industries. This direct relation is due to the significant leakages from small open economies. In fact, there is probably less of a direct relationship in larger economies that have larger multipliers. Governments vying for policies that tilt the balance in favour of the worker (or vice versa) should find this particularly informative especially if their economies depend significantly on foreign direct investment.

Fourth, multiplier analysis also shows that an increase in final demand yields an increase in GDP which is less than the initial change in expenditure. To a large extent, this result is due to the high dependence of the Maltese economy on imported products to provide the necessary inputs in the production process. This has important implications for the role of fiscal policy in small open economies and goes a long way in justifying the firm-specific targeted approach adopted by governments of small open economies when their economies are in distress. 
Fifth, the study led to the identification of sectors which are an important source of supply. The identification of these strategic sectors goes beyond the simple analysis of sectoral shares in the economy's total output, but is based on careful analysis of the inputs and outputs of each industry, including potential indirect effects that may be initiated following a change in final demand. The results show that the electricity, gas and water supply sector and the financial services sector had the highest forward linkages and lowest coefficients of variation, suggesting that the two sectors play a key role in providing inputs to a large number of domestic sectors in the economy. The policy-relevance of this point stems from the fact that inefficiencies and market distortions would be more damaging in those sectors that provide a key input to other industries and institutions.

Finally, the estimated multipliers provide a benchmark for alternative estimates which overcome the input-output model's fixed price assumption, such as those deriving from computable general equilibrium analysis. On the downside, this type of analysis would prove more informative to policy makers if it were conducted at a more disaggregated level such that it captures better the specificities of individual industries in the Maltese economy.

\section{References}

Baumol, W. J., \& Wolff, E. N. (1994). A Key Role for Input-Output Analysis in Policy Design. Regional Science and Urban Economics, 24, 93-113. http://dx.doi.org/10.1016/0166-0462(94)90021-3

Blake, A., Sinclair, M. T., \& Sugiyarto, G. (2003). The Economic Impact of Tourism in Malta: Input-Output Modelling. Report for the Malta Tourism Authority.

Bonnici, J. (1980). Integrating Input-Output and Keynesian Models: A Case Study of Malta. Unpublished doctoral dissertation, Simon Fraser University, Canada.

Boucher, M. (1976). Some further results on the linkage hypothesis. The Quarterly Journal of Economics, 90(2), 313-318. http://dx.doi.org/10.2307/1884633

Briguglio, L. (1992). Tourism Multipliers in the Maltese Economy. in Johnson, P. and Thomas, B. (eds.), Perspectives on Tourism Policy. Mansell, London, 76-80.

Dervis, K., de Melo, J., \& Robinson, S. (1982). General equilibrium models for development policy. Cambridge University Press, Cambridge, England.

Eurostat. (2008). Eurostat Manual of Supply, Use and Input-Output Tables. Luxembourg: Office for the Official Publications of the European Communities.

Ghosh, A. (1958). Input-Output Approach in an Allocation System. Economica, 25, 58-64. http://dx.doi.org/10.2307/2550694

Keynes, J. M. (1936). The General Theory of Employment, Interest and Money. London: MacMillan.

Leontief, W. (1966). Input-Output Economics. New York: Oxford University Press.

Mangion, M. L., \& Vella, L. (2000). The Economic Impact of Tourism in Malta. Malta Tourism Authority.

Miller, R. E., \& Blair, P. D. (2009). Input-Output Analysis: Foundations and Extensions. Cambridge University Press.

National Statistics Office. (1998). National accounts of the Maltese Islands. Valletta, Malta.

Rasmussen, P. (1956). Studies in inter-sectoral relations. Copenhagen: Einar Harks.

Schaffer, W. A. (1999). Regional Impact Models. Regional Research Institute, West Virginia University.

Walras, L. (1847). Elements of Pure Economics. London: Allen and Unwin.

Yotopoulos, P. A., \& Nugent, J. B. (1976). In Defence of a Test of the Linkage Hypothesis. Quarterly Journal of Economics, 90, 334-343. http://dx.doi.org/10.2307/1884636

\section{Notes}

Note 1. The sector includes sub-sectors such as health, education and recreational activities (including i-gaming).

Note 2. Fixed product sales structure assumes that each product has its own specific sales structure, irrespective of the industry where it is produced.

Note 3. Value added multipliers relate to both wages and profits whereas income multipliers relate only to wages. 